\title{
MicroRNA-219-5p functions as a tumor suppressor partially by targeting platelet-derived growth factor receptor alpha in colorectal cancer
}

\author{
G. B. XIONG, G. N. ZHANG, Y. XIAO*, B. Z. NIU, H. Z. QIU, B. WU, G. L. LIN, L. YOU, H. SHU \\ Department of General Surgery, Peking Union Medical College Hospital, Chinese Academy of Medical Sciences and Peking Union Medical \\ College, 100730 Beijing, PR China \\ *Correspondence: xiaoy@pumch.cn
}

Received January 9, 2015 / Accepted June 15, 2015

\begin{abstract}
Platelet-derived growth factor receptor (PDGFR) signaling pathway was involved in the progress of colorectal cancer (CRC). By using the bioinformatic system online, we found that PDGFRa is a potential target of miR-219-5p. However, the expression pattern and underlying mechanisms of miR-219-5p had not been elucidated in CRC. Herein, we first evaluated the expression of miR-219-5p in tumor tissues by real-time polymerase chain reaction. Next, we confirmed that PDGFR $\alpha$ is the target of miR-219-5p by using luciferase report. And then, we investigated the biological functions of miR-219-5p in vitro in cell proliferation and apoptosis as well as cell cycle by gain and loss of function strategies. Data shown that miR219-5p is down-regulated in CRC tissues compared with the corresponding matched normal tissues. PDGFRa was a direct target of miR-219-5p. Overexpression of miR-219-5p could inhibit cell proliferation, promote cell apoptosis and induce cell cycle arrest at the G1 phase. Furthermore, miR-219-5p suppressed the activation of the phosphatidylinositol 3-kinase/Akt signaling pathway and downregulated G1 cell-cycle-related protein cyclin D1, cyclin-dependent kinase (CDK) 4, and CDK6. Taken together, our results demonstrate that miR-219-5p functions as a tumor suppressor partially by targeting PDGFR $\alpha$ in colorectal cancer.
\end{abstract}

Key words: microRNA, colorectal cancer, miR-219-5p, PDGFR $\alpha$, PI3K/Akt

Colorectal cancer (CRC) is the third most common cancer [1] and one of the major causes of cancer mortality worldwide [2]. Over the past several decades, studies have revealed a multi-step process involved in the pathogenesis of this malignancy that includes both genetic and epigenetic changes $[3,4]$. Despite a number of molecular events have been identified, such as the p53, Wnt/ $\beta$-catenin, EGFR (epidermal growth factor receptor)- MAPK(mitogen-activated protein kinase), PI3K (phosphatidylinositol 3-kinase), nuclear factor-kappa B, and activator protein 1 (AP-1) pathways [3-5], the search for novel molecules that can be used as predictive, prognostic, and therapeutic targets of CRC remains a major issue.

MicroRNAs (miRNAs) are a large conserved class of short non-coding RNAs (20-24 nucleotides) that regulate gene expression mainly via complete or partial matching to target genes at the 3' untranslated region (UTR), causing suppression of protein translation or messenger RNA (mRNA) degradation [6-8]. Emerging evidence has shown that miRNAs play important roles in diverse cellular processes including cell proliferation, differentiation, and apoptosis [9]. Furthermore, studies have demonstrated that dysregulation of miRNAs is associated with human diseases, including various types of cancer [10]. miRNAs can serve as oncogenes or tumor suppressors in regulating angiogenesis, tumorigenicity, invasion, and metastasis [11-13]. Therefore, the dysregulation of certain miRNAs in primary tumor tissue or serum can act as predictive and prognostic biomarkers for cancer $[10,14]$. Moreover, miRNAs, along with their target genes, can also serve as therapeutic targets [15].

The PDGF receptor (PDGFR) signaling pathway is involved in the progression of cancer $[16,17]$ and can be activated through the autocrine system to promote cell proliferation and survival, improve migration and invasion abilities, and stimulate angiogenesis in cancer [16-18]. Recent research revealed that PDGFR was upregulated in CRC and correlated with advanced tumor stage and lymph node metastasis [19]. Moreover, high PDGFR $\beta$ tumor stromal expression was mainly responsible for tumor metastasis [20], and PDGFRa 
co-expression with VEGFR significantly linked to Kras codon 12 or 13 mutations in CRC [21]. Furthermore, blockade of PDGFR signaling pathways in tumor-associated stromal cells and pericytes could inhibit the progressive growth and metastasis of colon cancer cells [22]. Therefore, hampering this cell signal transduction pathway in CRC has proven to be an effective and feasible therapeutic strategy [23-25]. However, there are few reports that have examined miRNAs and PDGFR in CRC.

Using online bioinformatic system (DIANA LAB, PicTar, miRDB, Targetscan and miRanda, ect.), we found that PDGFR $\alpha$ was a potential target of miR-219-5p. Our findings primarily unveil the role of miR-219-5p in CRC and clarify the relationship between miR-219-5p and PDGFRa.

\section{Material and methods}

Patients and tissue samples. Twenty-five pairs of primary CRC and corresponding non-tumor adjacent tissue $(>5 \mathrm{~cm}$ away from the tumor tissue) samples from patients were obtained from PUMCH (Peking Union Medical College Hospital, Beijing, China) with patients' informed consent in 2012. The study was approved by PUMCH Research Ethics Committee.

Cell culture and reagents. Human CRC cell line HCT116 was cultured in IMDM medium (Hyclone, Thermo Fisher Scientific Inc., Waltham, MA) supplemented with $10 \%$ fetal bovine serum (Hyclone), $100 \mathrm{IU} / \mathrm{mL}$ penicillin, and $100 \mu \mathrm{g} / \mathrm{mL}$ streptomycin in humidified $5 \% \mathrm{CO} 2$ at $37^{\circ} \mathrm{C}$. The miR-219-5p mimics (5'-UGAUUGUCCAAACGCAAUUCU-3', 5'-AAUUGCGUUUGGACAAUGAUU-3'), negative control (5'-UUCUCCGAACGUGUCACGUTT-3', 5'-ACGUGACACGUUCGGAGAATT-3), miR-219-5p inhibitor (5'-AGAAUUGCGUUUGGACAAUCA-3), and inhibitor control (5'-CAGUACUUUUGUGUAGUACAA-3') were purchased from Invitrogen (Carlsbad, CA, USA).

Cell transfection. Transfection was performed with Lipofectamine 2000 Reagent (Invitrogen) according to the manufacturer's instructions. A final concentration of 100 $\mathrm{nM}$ of mimics and $150 \mathrm{nM}$ of inhibitor and their respective negative controls were used for each transfection. RNA and proteins were harvested at 48 or $72 \mathrm{~h}$ after transfection.

RNA extraction and quantitative reverse transcriptionpolymerase chain reaction (qRT-PCR). Total RNA was extracted from tissues and cell pellets using Trizol reagent (Invitrogen), according to the manufacturer's instructions. For miR-219-5p expression, synthesis of complementary DNA and real-time PCR were performed using the TaqMan MicroRNA Reverse Transcription Kit and the TaqMan MicroRNA Assay kit (Applied Biosystems) according to the standard TaqMan MicroRNA Assay protocol. Levels of U6 RNA (RNU6B; Applied Biosystems) were determined and used as an endogenous control.

For PDGFRa quantitative assay, total RNA was reverse transcribed using the reverse transcription kit (Promega,
Madison, WI) according to the manufacturer's instructions. Real-time PCR was performed using the SYBR Green Master Mix (Takara, Japan). GAPDH were served as the endogenous control.

PDGFRa Forward primer: 5' -TCTAGACCG GCCTGAGAAACACTATTTGTG 3-', Reverse primer: 5' TCTAGAACATGAACAGGGGCATTCGTAATACA -3';

GAPDH Forward primer: 5'-CGGAGTCAACGGATTTGGTCGTAT-3', Reverse primer: 5'-AGCCTTCTCCATGGTGGTGAAGAC-3'.Relative gene expression levels were calculated and normalized using the $2^{-\Delta \Delta \mathrm{Ct}}$ method. All real-time PCR reactions were run in triplicate.

Cell proliferation assay. Cell proliferation was determined using a cell count kit (CCK-8) (Dojindo Laboratories, Kumamoto, Japan) according to the manufacturer's instructions. Briefly, cells were seeded into six-well plates at $5 \times 10^{5} \mathrm{cells} /$ well and transfected with miR-219-5p mimics, miR-219-5p inhibitor, or negative control the next day. After $24 \mathrm{~h}$, cells were trypsinized and reseeded in 96-well plates $\left(1 \times 10^{3}\right.$ cells/ well). CCK- 8 assay was performed at $0,24,48,72$, and $96 \mathrm{~h}$. The absorbance of each well was measured with a microplate reader (Wellscan MK3, Thermo/Labsystems, Finland) set at sub $450-630 \mathrm{~nm}$.

Cell apoptosis assay. The cell apoptosis ratio was evaluated using the Annexin V-FITC Apoptosis Detection Kit (Beyotime, Shanghai, China). At $72 \mathrm{~h}$ after transfection, cells were harvested and resuspended in binding buffer containing Annexin V-FITC and propidium iodide (PI) according to the manufacturer's instructions. Cells were evaluated as viable cells, necrotic cells, and apoptotic cells using a FACSARIA flow cytometer (Becton Dickenson, San Jose, CA, USA).

Cell cycle analysis. For cell-cycle analysis, $48 \mathrm{~h}$ after transfection, the cells were harvested and fixed in 70\% ethanol overnight and stained with PI (BD Pharmingen, San Jose, CA, USA) according to the manufacturer's instructions. The stained cells were sorted by FACSCan (BD Biosciences, Franklin Lakes, NJ, USA) 30 min after staining.

Western blot. Total protein was extracted and protein concentrations were measured by the BCA protein assay kit (Beyotime). Western blot analysis was performed according to standard procedures. Protein samples were separated on $8 \%$ or $10 \%$ Tris-polyacrylamide gel by electrophoresis and blotted onto polyvinylidenefluoride membranes (PVDF; Millipore, Billerica, MA, USA). The membranes were immunoblotted overnight at $4{ }^{\circ} \mathrm{C}$ with primary antibodies as follows: rabbit monoclonal antibodies against human PDGFRa (\#5241S), AKT (\#4685), p-AKT (\#4060), GSK-3 $\beta$ (\#12456S), p-GSK-3 $\beta$ (\#5558S), Bad (\#9268), p-Bad (\#5284S), CDK6 (\#13331S), and $\beta$-actin (\#4970) and mouse monoclonal antibodies against human caspase-9 (\#9508S), CDK4 (\#2906S) and cyclin D1 (\#2926S) (1:1000 dilution; Cell Signaling Technology, USA). The horseradish peroxidase-conjugated goat IgG (1:3000 dilution; Beyotime) secondary antibody was incubated with the membrane for $1 \mathrm{~h}$ after three washes with TBST. Protein 
bands were visualized with an enhanced chemiluminescence system (Millipore).

Dual-luciferase reporter assay. For luciferase reporter experiments, the wild-type or mutant PDGFRa target sequence was cloned into the pmiR-RB-Report ${ }^{\mathrm{mot}}$ luciferase reporter plasmid (RiboBio Co. Ltd., China) to generate pmiRPDGFRa-wt and pmiR-PDGFRa-mut, respectively. HCT116 cells were plated into 24 -well plates at $50-60 \%$ confluence $24 \mathrm{~h}$ before transfection. A mixture of miR-219-5p mimics or negative control and pmiR-PDGFRa-wt or pmiR-PDGFRamut was co-transfected into cells using Lipofectamine 2000 reagent. After $48 \mathrm{~h}$, cells were harvested and assayed with the Dual Luciferase Reporter Assay System (Promega, USA) according to the manufacturer's instructions.

Statistical analysis. All experiments were performed in triplicate. The experimental results are presented as the mean \pm standard deviation (SD) and compared by the Student's $\mathrm{t}$ test or the Mann-Whitney U test. All statistical analyses were performed with SPSS 13.0 (SPSS Inc., Chicago, IL), and a value of $\mathrm{P}<0.05$ was considered to indicate statistical significance.

\section{Results}

Expression of miR-219-5p in CRC. We assessed the expression of miR-219-5p in 25 pairs of matched human CRC tissue and normal epithelial tissue specimens using miRNA TaqMan real-time PCR. As shown in Fig. 1, miR-219-5p expressed at a lower level in tumor sample compared with the corresponding matched normal tissue $(p<0.001)$. We then investigated the biological functions of miR-219-5p in HCT116 cells by gain or loss of function in vitro.

MiR-219-5p inhibits CRC cells proliferation in vitro. To characterize the functional role of miR-219-5p in CRC tumorigenesis, we first examined the effect of miR-219-5p on HCT116 cell proliferation using CCK8 assay. Overexpression of miR-219-5p significantly inhibited the proliferation of cells, whereas miR-219-5p inhibitor promoted the proliferation of HCT116 cells (Fig. 2A).

MiR-219-5p promoted CRC cells apoptosis in vitro. We next evaluated the effects of miR-219-5p on apoptosis. At $72 \mathrm{~h}$ after transfection, the total levels of apoptotic cells in the miR-219-5p mimic-transfected group were significantly increased compared with cells transfected with the negative control $(\mathrm{P}<0.05)$. The percentage of apoptotic cells in the miR-219-5p inhibitor-transfected group was lower than the inhibitor control group $(\mathrm{P}<0.05)$ (Fig. $2 \mathrm{~B})$.

MiR-219-5p induced G1 cell cycle arrest in CRC cells. To assess the mechanism of the anti-proliferative effect of miR-219-5p in HCT116 cells, we examined whether growth inhibition was associated with specific effects on cell-cycle progression. Flow cytometric analysis showed that the number of cells in the G1 phase was greater in the miR-219-5p mimic group than in the negative control group $(\mathrm{P}<0.01)$, and the number of cells in the $S$ phase in the miR-219-5p mimic group

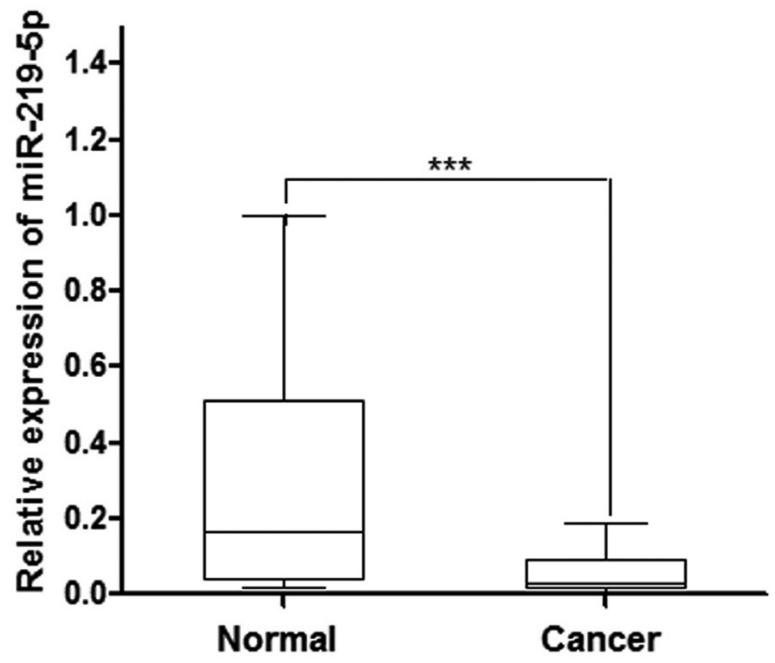

Figure 1. Expression levels of miR-219-5p in 25 paired CRC and adjacent non-tumor tissues. The mean level of miR-219-5p expression was significantly lower in CRCs than that in normal tissues (from the Mann-Whitney $\mathrm{U}$ test, $\left.{ }^{* *} \mathrm{P}<0.001\right)$. The data are shown as mean $\pm \mathrm{SD}$.

was sharply reduced compared with controls $(\mathrm{P}<0.01)$. In contrast, compared with the inhibitor control, HCT116 cells transfected with miR-219-5p inhibitor showed a decrease in the number of cells in the G1 phase $(\mathrm{P}<0.01)$ and an increase in the number of cells in the $S$ phase $(\mathrm{P}<0.01)$ (Fig. 3).

PDGFRa was a direct target of miR-219-5p. The publicly available programs DIANA LAB (http://diana.cslab.ece.ntua. gr), miRanda (http://www.microrna.org) TargetScan (http:// www.targetscan.org) and PicTar (http://pictar.mdc-berlin.de/ cgi-bin/PicTar_vertebrate.cgi) have been indicated miR-219$5 p$ potential targets PDGFRa (Fig. $4 \mathrm{~A}$ ). We then performed a luciferase reporter assay to verify whether PDGFRa was a direct target of miR-219-5p. Co-transfection of miR-219-5p mimics and a luciferase reporter vector harboring wild-type PDGFR $\alpha$ (pmiR-PDGFR $\alpha$-wt) resulted in significantly decreased luciferase activity in HCT116 cells compared with co-transfection with the respective control $(P<0.05)$. Notably, miR-219-5p mimics had no effect on the luciferase activity of the pmiR-PDGFR $\alpha$-mut construct containing the mutated putative miR-219-5p binding sequence in the 3'-UTR of PDGFR $\alpha$ mRNA (Fig. 4B). These data suggest that PDGFRa is one of the direct targets of miR-219-5p.

To further confirm PDGFRa as a downstream target of miR-219-5p, we examined PDGFR $a$ mRNA and protein levels in HCT116 cells transfected with miR-219-5p mimics or negative control by RT-PCR and western blot. Transfection with 100 pmol of miR-219-5p mimics in HCT116 cells led to a sharp increase in miR-219-5p expression as detected by RT-PCR compared with negative controls $(\mathrm{P}<0.001)$ (Fig. $4 \mathrm{C})$. Furthermore, the increased endogenous miR-219-5p levels were associated with significantly decreased endogenous PDGFRa mRNA and protein expression (Fig. 4D, E). In 
A

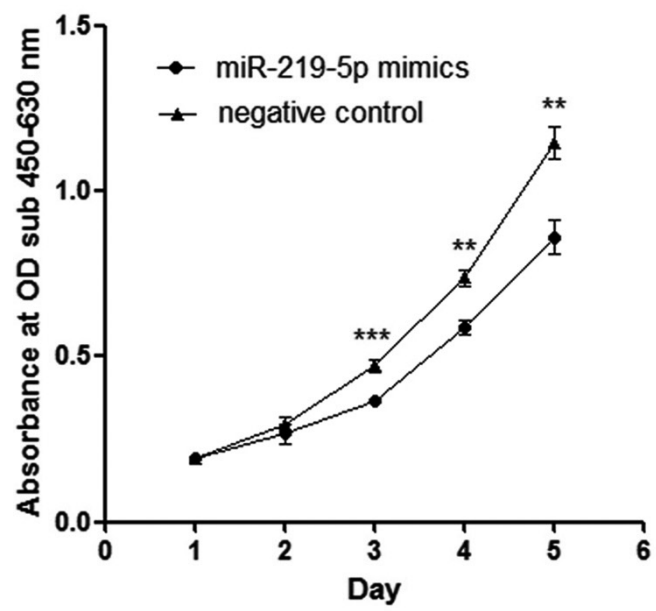

B
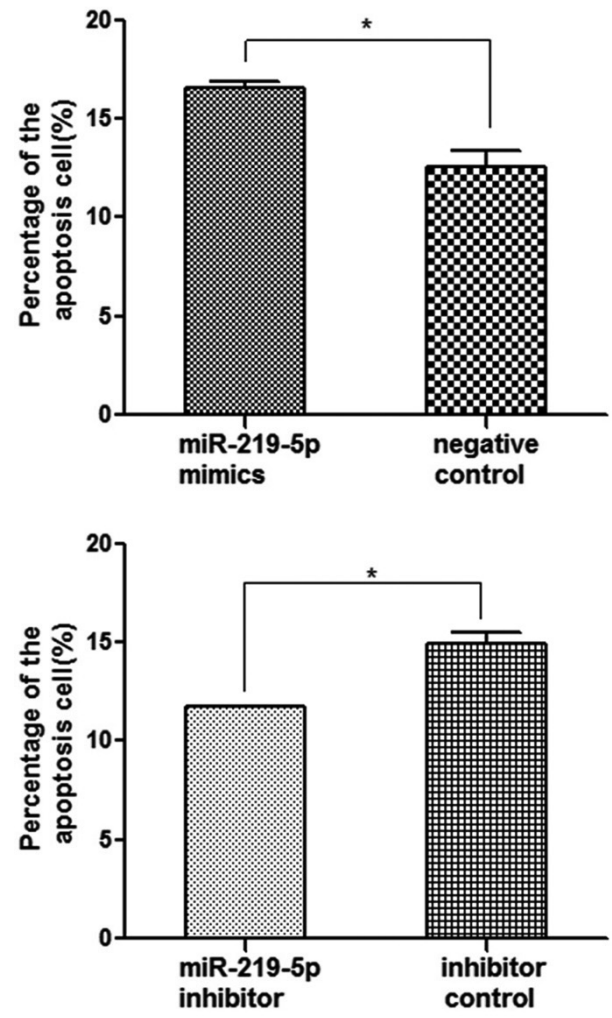

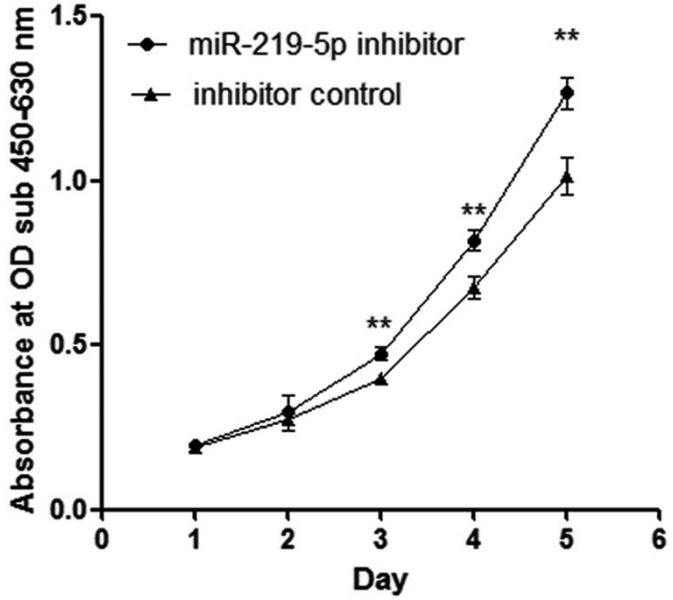

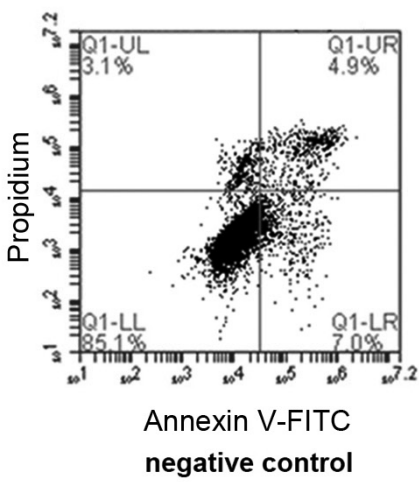
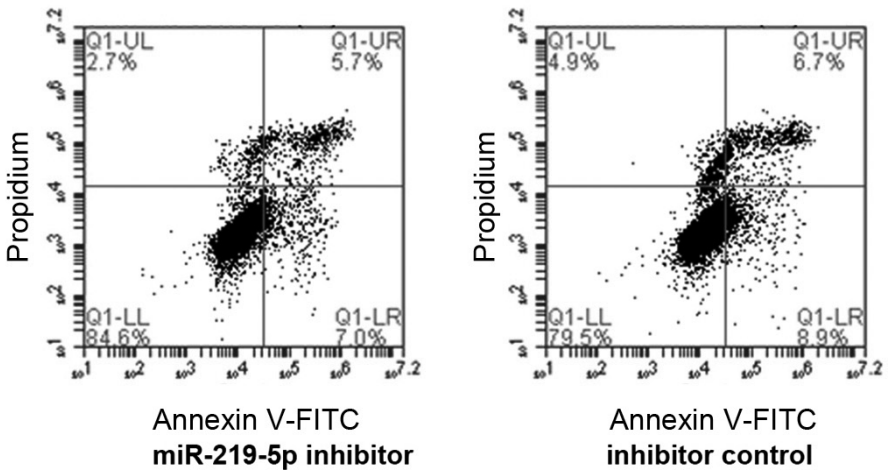

Figure 2. Effects of transfection with miR-219-5p mimics, miR-219-5p inhibitor, and the respective nonspecific control on HCT116 cell proliferation (A) and apoptosis (B). Results are shown as mean \pm SD (from the Student's t test, ${ }^{*} P<0.05,{ }^{* *} P<0.01,{ }^{* * *} P<0.001$ ).

contrast, transfection with 150 pmol of miR-219-5p inhibitor showed a decrease of miR-219-5p expression and an increase PDGFRa mRNA and protein expression $(\mathrm{P}<0.05)$ compared with the inhibitor control (Fig. 4D, E). These data suggest that PDGFRa is a direct target of miR-219-5p.

Overexpression of miR-219-5p reduced the activation of PI3 Kinase pathway. Next, we investigated the molecular mechanisms responsible for the anti-tumor effects of miR219-5p in HCT116 cells observed above. Overexpression of miR-219-5p led to decreased activation levels of the PI3K pathway as assayed by the decreased phosphorylation of Ser473 of Akt, without any change in the levels of total Akt. Furthermore, the anti-proliferation and increased apoptosis effects of miR-219-5p in HCT116 cells was also associated 

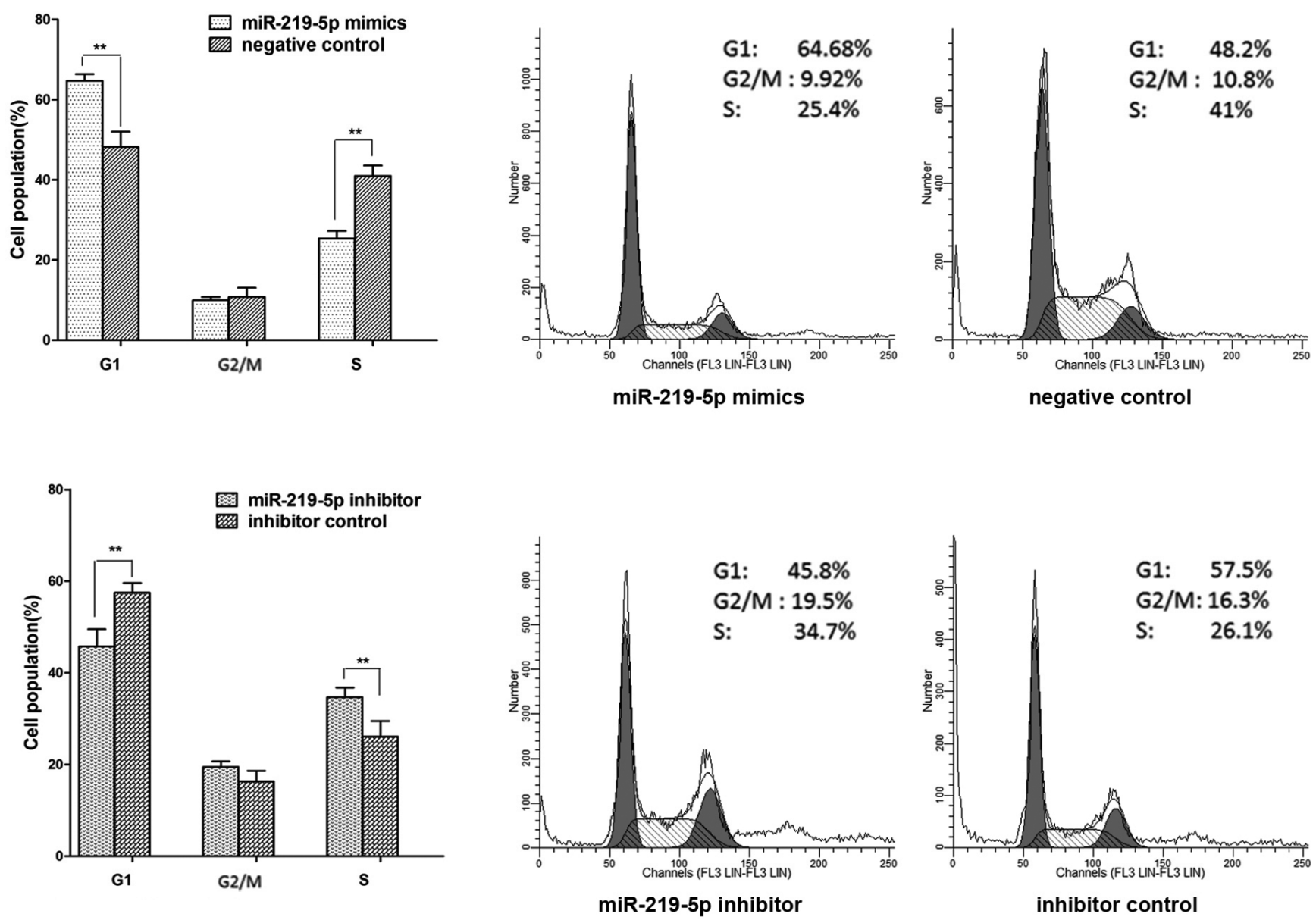

Figure 3. Effects of miR-219-5p played on HCT116 cell cycle. Results are shown as mean \pm SD (from the Student's $t$ test, ${ }^{, *} P<0.01$ ).

with downregulation of the levels of p-GSK-3 $\beta$ and p-Bad, and upregulation of the level of cleaved caspase-9 (Fig. 5A). We further analyzed the predicted G1 cell cycle related proteins, cyclinD1, CDK4 and CDK6. As shown in Fig. 4B, upon overexpression of miR-219-5p, cyclin D1, CDK4, and CDK6 protein levels were markedly reduced (Fig. 5B).

\section{Discussion}

The identification of cancer-specific miRNAs and their targets was critical for understanding their role in tumorigenesis. There has been an increasing accumulation of literature reporting the deregulation of miRNAs in CRC over the past a few years. Several studies have also suggested the importance of miRNAs expression profiling in CRC in their utility as diagnostic and prognostic signatures [15]. In present study, we first demonstrated that miR-219-5p expression was significantly decreased in colorectal cancer tissues when compared with the corresponding matched normal tissues. We found that miR-219-5p inhibited cell proliferation, promoted cell apoptosis and induced cell cycle arrest at the G1 phase in
HCT116 cells. We also revealed that miR-219-5p decreased the activation levels p-Akt and p-GSK-3 $\beta$ to inhibit cell growth, and downregulated the expression of $\mathrm{p}$-Bad and upregulated the cleave Caspase- 9 to promote cell apoptosis. The expression of G1 cell cycle related protein CyclinD1, CDK4 and CDK6 were also reduced markedly. Therefore, miR-219-5p may act as a tumor suppressor in CRC.

MiR-219-5p was downregulated in several solid tumors, such as hepatocellular carcinoma, glioblastoma and papillary thyroid carcinoma [26-28]. Several biological targets of miR-219-5p have also been identified recently. For example, miR-219-5p was found to inhibit hepatocellular carcinoma cell proliferation by targeting glypican-3 [26]. In glioblastoma, miR-219-5p targeted EGFR to regulate the receptor tyrosine kinase pathway [27]. In papillary thyroid carcinoma, miR-219-5p suppressed cell proliferation and migration, and promoted apoptosis by directly decreasing estrogen receptor $\alpha$ [28]. Besides, miR-219-1-3p and miR-219-2-3p functioned as tumor suppressor in pancreatic cancer and gastric cancer [29-30]. And the polymorphisms of miR-219-1 in rs 213210 associated with a significantly worse survival and increased 
A

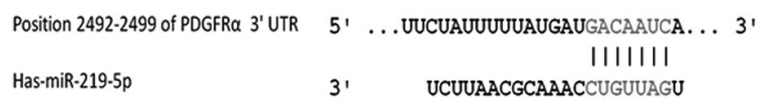

C

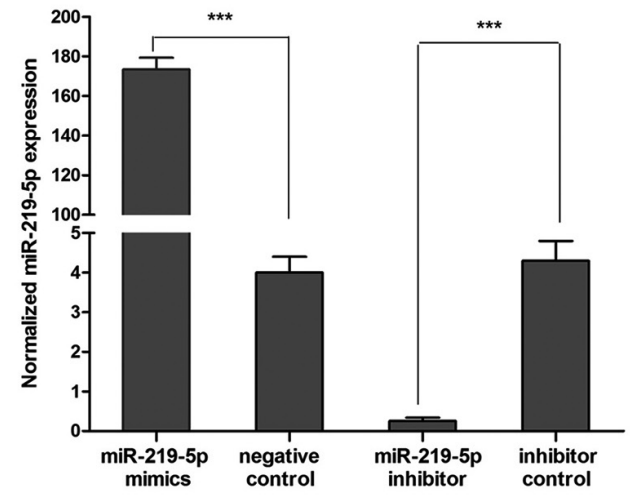

$\mathrm{E}$

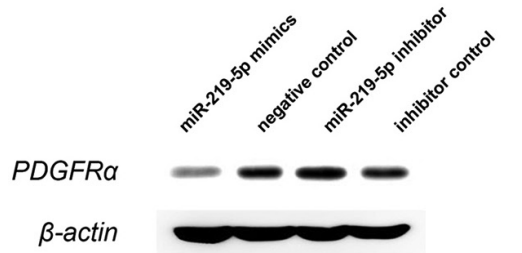

B

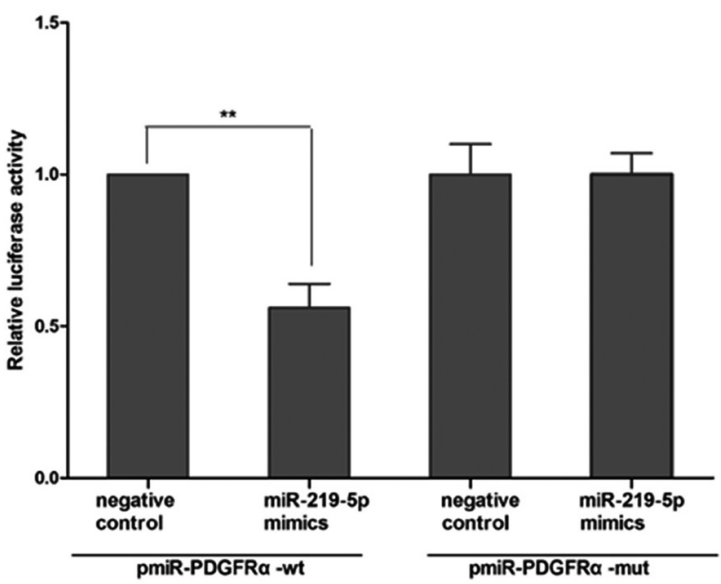

D

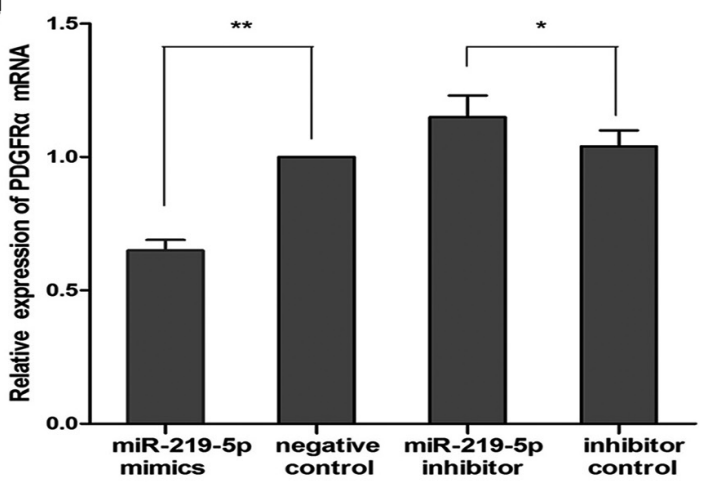

Figure 4. PDGFRa is a direct target of miR-219-5p. (A)Targetscan predicted that miR-219-5p would target the 3'UTR of PDGFRa. (B) Luciferase reporter assay in HCT116 cells transfected with reporter vectors containing wild-type or mutant PDGFRa 3'-UTR (pmiR-PDGFRa-wt and pmiR-PDGFRamut). Relative luciferase expression was normalized to Renilla luciferase activity. (C) Relative expression of miR-219-5p by qRT-PCR in HCT116 cells transfected with miR-219-5p mimics, miR-219-5p inhibitor and the respective nonspecific control. (D, E) Analysis of endogenous PDGFRa mRNA and protein expression levels in HCT116 cells transfected with miR-219-5p mimics, miR-219-5p inhibitor, and the respective nonspecific control by RT-PCR and western blot. The data are shown as mean $\pm \mathrm{SD}$ (from the Student's t test, ${ }^{\star} P<0.05,{ }^{\star *} P<0.01,{ }^{\star * *} P<0.001$ ).

risk of relapse in CRC [31]. Here, we reported that miR-219$5 p$ was significantly decreased and directly targeted PDGFRa, indicating that miR-219-5p may mediate its effects by negative regulating PDGFRa in CRC.

PDGFRa was involving in the progression of cancer [16] and upregulated in CRC [32]. Welher et al. reported that PDGFRa was overexpressed in $83 \%$ of CRC specimens and significantly correlated with lymph node metastasis and advanced UICC stages III/IV in older patients [19]. Zhu et al. revealed that the 3-year overall and progression-free survival rates were significantly lower in patients with high PDGFRa expression than in those with low PDGFRa expression [33]. Blockade of PDGFRa diminished the cell proliferation and migration in CRC [34-36]. So, PDGFRa played an important role in CRC tumorigenesis.

However, modulation the expression of PDGFRa by miRNAs has previously been reported. PDGFRa was identified as a key regulator of the miRNA-mediated network of oncogenic pathways in glioblastoma $[37,38]$. MiR-34a $[39,40]$ and miR-
128 [41] directly targeted the 3'-UTR of PDGFRa and could function as tumor suppressors, with therapeutic potential for glioma. MiR-218-2 targeted PDGFRa to inhibit cell invasion, migration, and proliferation in thyroid cancer [42]. MiR-126 regulated PDGFRa expression on migratory behavior of human osteoblasts [43]. Moreover, PDGFRa was also a direct therapeutic target in 5\%-8\% gastrointestinal stromal tumors (GIST) [44, 45].

We demonstrated that the blockade of the PDGFRa signal pathway by overexpression miR-219-5p led to decreased expression of p-Akt and changes in the levels of p-GSK-3 $\beta$, p-Bad, cleaved caspase-9, and cyclin D1 in HCT116 cells. PDGFR was a component of the receptor tyrosine kinase (RTK) pathway, and its downstream signaling pathway was mainly PI3K/Akt as shown in the KEGG pathway database (http://www.genome.jp/kegg/pathway.html). Therefore, we chose to evaluate the expression levels of Akt, GSK-3 $\beta$, Bad, and caspase-9 to analyze the molecular mechanism of miR-219-5p regulation of CRC cells (Fig. 4C). In the 


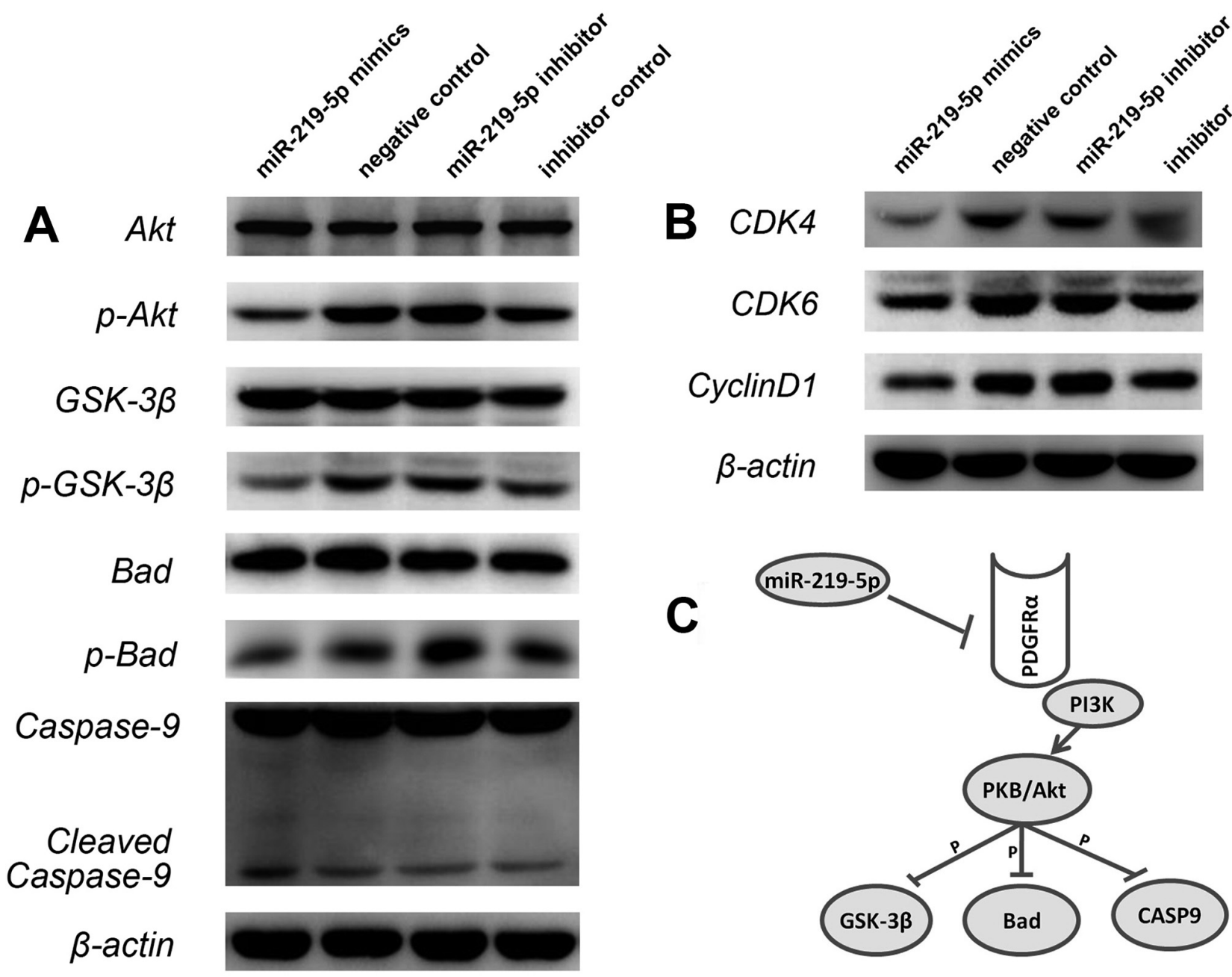

Figure 5. miR-219-5p inhibits HCT116 cell proliferation and promotes apoptosis via decreasing activation of the PI3K/Akt pathway. (A, B) The expression levels of relative protein by Western blot. Cells were transfected with miR-219-5p mimics, miR-219-5p inhibitor and their respective nonspecific control. (C) The signal transduction pathway of miR-219-5p played in CRC.

Wnt $/ \beta$-catenin signaling pathway, GSK-3 $\beta$ could destabilize $\beta$-catenin by phosphorylation and promoted its degradation, then repressed its recruitment to TCF/LEF complexes, thereby inhibited cell proliferation [46]. P-GSK-3 $\beta$, which was the inactivated form of GSK-3 $\beta$, was downregulated by miR-219-5p, leading to inhibition of cell proliferation. In the cell apoptosis pathway, p-Bad was the inactivate form of Bad [47], while cleaved caspase- 9 was the active form of caspase-9 [48]. After downregulation of p-Bad and upregulation of cleaved caspase- 9 by miR-219-5p, Bad and cleaved caspase- 9 could then induce cell apoptosis. CDK6 and CDK4 could communicate with CyclinD1 to enhance the G1 phase to enter S phase [42], when their expression levels down-regulated by miR-219-5p, the cell cycle was arrested in G1 phase.

Thus, our results show that the anti-tumor effect of miR219-5p in CRC was a result of reduced activation of the PI3K pathway (Fig. 5C). Overexpression of miR-219-5p reduced the activation of PI3K/Akt pathway, suggesting that the down-regulation of miR-219-5p could be contributing to the increased activity of these pathways in CRC. However, PDGFRa, which was littler detected in colon cancer cells [35], could activate other RTK pathways for expanding its effect when sensitized [17]. And our experiment didn't perform the exogenous PDGFR $\alpha$ rescue assay in miR-219-5p overexpressed cells to illustrate the specificity of miR-219-5p/ PDGFR $\alpha$ axis. Therefore, miR-219-5p could act as a tumor suppressor partially by targeting PDGFRa to decrease the activation of the receptor tyrosine kinase pathway.

In conclusion, our findings provide insights towards potential diagnostic and therapeutic applications for CRC involving modulation of miR-219-5p. Our results will help contribute to the development of new therapeutic strategies for CRC. 


\section{References}

[1] BRENNER H, KLOOR M, POX CP. Colorectal cancer. Lancet. 2014; 383: 1490-502. http://dx.doi.org/10.1016/ $\underline{\text { S0140-6736(13)61649-9 }}$

[2] SIEGEL R, MA J, ZOU Z, JEMAL A. Cancer statistics, 2014. CA Cancer J Clin. 2014; 64: 9-29. http://dx.doi.org/10.3322/ caac. 21208

[3] FEARON ER. Molecular genetics of colorectal cancer. Annu Rev Pathol. 2011; 6: 479-507. http://dx.doi.org/10.1146/ annurev-pathol-011110-130235

[4] VENKATACHALAM R, LigTENBERG MJ, HOOGERBRUGGE N, DE BRUIJN DR, KUIPER RP, et al. The epigenetics of (hereditary) colorectal cancer. Cancer Genet Cytogenet. 2010; 203: 1-6. http://dx.doi.org/10.1016/j. cancergencyto.2010.08.013

[5.] WALTHER A, JOHNSTONE E, SWANTON C, MIDGLEY $\mathrm{R}$, TOMLINSON I, et al. Genetic prognostic and predictive markers in colorectal cancer. Nat Rev Cancer. 2009; 9: 489-99. http://dx.doi.org/10.1038/nrc2645

[6] BARTEL DP. MicroRNAs Genomics, Biogenesis, Mechanism, and Function. Cell. 2004; 116: 281-97. http://dx.doi. org/10.1016/S0092-8674(04)00045-5

[7] CARTHEW RW, SONTHEIMER EJ. Origins and Mechanisms of miRNAs and siRNAs. Cell. 2009; 136: 642-55. http:// dx.doi.org/10.1016/j.cell.2009.01.035

[8] FILIPOWICZ W, BHATTACHARYYA SN, SONENBERG $\mathrm{N}$. Mechanisms of post-transcriptional regulation by microRNAs: are the answers in sight? Nat Rev Genet. 2008; 9: 102-14. http://dx.doi.org/10.1038/nrg2290

[9] AMBROS V. MicroRNA Pathways in Flies and Worms. Cell. 2003; 113: 673-6. http://dx.doi.org/10.1016/S0092-8674(03)00428-8

[10] CALIN GA, CROCE CM. MicroRNA signatures in human cancers. Nat Rev Cancer. 2006; 6: 857-66. http://dx.doi. org/10.1038/nrc1997

[11] CROCE CM. Causes and consequences of microRNA dysregulation in cancer. Nat Rev Genet. 2009; 10: 704-14. http:// dx.doi.org/10.1038/nrg2634

[12] SHENOUDA SK, ALAHARI SK. MicroRNA function in cancer: oncogene or a tumor suppressor? Cancer Metastasis Rev. 2009; 28: 369-78. http://dx.doi.org/10.1007/s10555-009 -9188-5

[13] BARANWAL S, ALAHARI SK. miRNA control of tumor cell invasion and metastasis. Int J Cancer. 2010; 126: 1283-90. http://dx.doi.org/10.1002/ijc.25014

[14] LEE YS, DUTTA A. MicroRNAs in Cancer. Annu Rev Pathol. 2009; 4: 199-227. http://dx.doi.org/10.1146/annurev. pathol.4.110807.092222

[15] SLABY O, SVOBODA M, MICHALEK J, VYZULA R. MicroRNAs in colorectal cancer: translation of molecular biology into clinical application. Mol Cancer. 2009; 8: 102. http:// dx.doi.org/10.1186/1476-4598-8-102

[16] BOARD R, JAYSON GC. Platelet-derived growth factor receptor (PDGFR): a target for anticancer therapeutics. Drug Resist Updat. 2005; 8: 75-83. http://dx.doi.org/10.1016/j. drup.2005.03.004
[17] FAROOQI AA, WASEEM S, RIAZ AM, DILAWAR BA, MUKHTAR S, et al. PDGF: the nuts and bolts of signalling toolbox. Tumour Biol. 2011; 32: 1057-70. http://dx.doi. org/10.1007/s13277-011-0212-3

[18] HELDIN CH, OSTMAN A, RONNSTRAND L. Signal transduction via platelet-derived growth factor receptors. Biochim Biophys Acta. 1998; 1378: F79-113. http://dx.doi.org/10.1016/ s0304-419x(98)00015-8

[19] WEHLER TC, FRERICHS K, GRAF C, DRESCHER D, SCHIMANSKI K, et al. PDGFRalpha/beta expression correlates with the metastatic behavior of human colorectal cancer a possible rationale for a molecular targeting strategy. Oncol Rep. 2008; 19: 697-704.

[20] KITADAI Y, SASAKI T, KUWAI T, NAKAMURA T, BUCANA CD, et al. Expression of activated platelet-derived growth factor receptor in stromal cells of human colon carcinomas is associated with metastatic potential. Int J Cancer. 2006; 119: 2567-74. http://dx.doi.org/10.1002/ijc.22229

[21] SCHIMANSKI CC, ZIMMERMANN T, SCHMIDTMANN I, GOCKEL I, LANG H, et al. K-ras mutation status correlates with the expression of VEGFR1, VEGFR2, and PDGFRalpha in colorectal cancer. Int J Colorectal Dis. 2010; 25: 181-6. http://dx.doi.org/10.1007/s00384-009-0843-7

[22] KITADAI Y, SASAKI T, KUWAI T, NAKAMURA T, BUCANA CD, et al. Targeting the expression of platelet-derived growth factor receptor by reactive stroma inhibits growth and metastasis of human colon carcinoma. Am J Pathol. 2006; 169: 2054-65. http://dx.doi.org/10.2353/ajpath.2006.060653

[23] GUO FJ, ZHANG WJ, LI YL, LIU Y, LI YH, et al. Expression and functional characterization of platelet-derived growth factor receptor-like gene. World J Gastroenterol. 2010; 16: 1465. http://dx.doi.org/10.3748/wjg.v16.i12.1465

[24] CAPDEVILA J, MENDEZ G, MACARULLA T, RAMOS FJ, CASADO E, et al. New approaches and targets in advanced colorectal cancer : the molecular targets era. Expert Rev Anticancer Ther. 2007; 7: 1027-41. http://dx.doi. org/10.1586/14737140.7.7.1027

[25] GROTHEY A, VAN CUTSEM E, SOBRERO A, SIENA S, FALCONE A, et al. Regorafenib monotherapy for previously treated metastatic colorectal cancer (CORRECT): an international, multicentre, randomised, placebo-controlled, phase 3 trial. Lancet. 2013; 381: 303-12. http://dx.doi.org/10.1016/ $\underline{\text { S0140-6736(12)61900-X }}$

[26.] HUANG N, LIN J, RUAN J, SU N, QING R, et al. MiR-219 $-5 p$ inhibits hepatocellular carcinoma cell proliferation by targeting glypican-3. FEBS Lett. 2012; 586: 884-91. http:// dx.doi.org/10.1016/j.febslet.2012.02.017

[27] RAO SA, ARIMAPPAMAGAN A, PANDEY P, SANTOSH V, HEGDE AS, et al. miR-219-5p inhibits receptor tyrosine kinase pathway by targeting EGFR in glioblastoma. PloS one. 2013; 8: e63164. http://dx.doi.org/10.1371/journal.pone.0063164

[28] HUANG C, CAI Z, HUANG M, MAO C, ZHANG Q, et al. miR-219-5p modulates cell growth of papillary thyroid carcinoma by targeting estrogen receptor $\alpha$. J Clin Endocrinol Metab. 2015; 100: E204-13. http://dx.doi.org/10.1210/jc.2014-2883

[29] LAHDAOUI F, DELPU Y, VINCENT A, RENAUD F, MESSAGER $M$, et al. miR-219-1-3p is a negative regulator of 
the mucin MUC4 expression and is a tumor suppressor in pancreatic cancer. Oncogene. 2015; 34: 780-8. http://dx.doi. org/10.1038/onc.2014.11

[30] LEI H, ZOU D, LI Z, LUO M, DONG L, et al. MicroRNA-219 $-2-3 p$ functions as a tumor suppressor in gastric cancer and is regulated by DNA methylation. PloS one. 2013; 8: e60369. http://dx.doi.org/10.1371/journal.pone.0060369

[31] PARDINI B, ROSA F, NACCARATI A, VYMETALKOVA V, YE Y, et al. Polymorphisms in microRNA genes as predictors of clinical outcomes in colorectal cancer patients. Carcinogenesis. 2015; 36: 82-6. http://dx.doi.org/10.1093/carcin/ bgu224

[32] CRAVEN RJ, XU LH, WEINER TM, FRIDELL YW, DENT GA, et al. Receptor tyrosine kinases expressed in metastatic colon cancer. Int J Cancer. 1995; 60: 791-7. http://dx.doi. org/10.1002/ijc.2910600611

[33] ZHU HT, HAN J, MA L. Expression and clinical significance of PDGFRalpha and PDGFRbeta in colorectal cancer. Ai Zheng. 2008; 27: 654-60.

[34] LIU C, LI J, XIANG X, GUO L, TU K, et al. PDGF receptor- $\alpha$ promotes TGF- $\beta$ signaling in hepatic stellate cells via transcriptional and posttranscriptional regulation of TGF- $\beta$ receptors. Am J Physiol Gastrointest Liver Physiol. 2014; 307: G749-59. http://dx.doi.org/10.1152/ajpgi.00138.2014

[35] KAULFUSS S, SEEMANN H, KAMPE R, MEYER J, DRESSEL R, et al. Blockade of the PDGFR family together with SRC leads to diminished proliferation of colorectal cancer cells. Oncotarget. 2013; 4: 1037-49. http://dx.doi.org/10.18632/ oncotarget.1085

[36] YUGE R, KITADAI Y, SHINAGAWA K, ONOYAMA M, TANAKA S, et al. mTOR and PDGF pathway blockade inhibits liver metastasis of colorectal cancer by modulating the tumor microenvironment. Am J Pathol. 2015; 185: 399-408. http://dx.doi.org/10.1016/j.ajpath.2014.10.014

[37] SUMAZIN P, YANG X, CHIU HS, CHUNG WJ, IYER A, et al. An extensive microRNA-mediated network of RNARNA interactions regulates established oncogenic pathways in glioblastoma. Cell. 2011; 147: 370-81. http://dx.doi. org/10.1016/j.cell.2011.09.041

[38] GENOVESE G, ERGUN A, SHUKLA SA, CAMPOS B, HANNA J, et al. microRNA regulatory network inference identifies miR-34a as a novel regulator of TGF-beta signaling in glioblastoma. Cancer discovery. 2012; 2: 736-49. http:// dx.doi.org/10.1158/2159-8290.CD-12-0111

[39] LI Y, GUESSOUS F, ZHANG Y, DIPIERRO C, KEFAS B, et al. MicroRNA-34a inhibits glioblastoma growth by targeting multiple oncogenes. Cancer Res. 2009; 69: 7569-76. http:// dx.doi.org/10.1158/0008-5472.CAN-09-0529
[40] SILBER J, JACOBSEN A, OZAWA T, HARINATH G, PEDRAZA A, et al. miR-34a repression in proneural malignant gliomas upregulates expression of its target PDGFRA and promotes tumorigenesis. PloS one. 2012; 7: e33844. http:// dx.doi.org/10.1371/journal.pone.0033844

[41] PAPAGIANNAKOPOULOS T, FRIEDMANN-MORVINSKI D, NEVEU P, DUGAS JC, GILL RM, et al. Pro-neural miR-128 is a glioma tumor suppressor that targets mitogenic kinases. Oncogene. 2012; 31: 1884-95. http://dx.doi. org/10.1038/onc. 2011.380

[42] GUAN H, WEI G, WU J, FANG D, LIAO Z, et al. Downregulation of miR-218-2 and its host gene SLIT3 cooperate to promote invasion and progression of thyroid cancer. J Clin Endocrinol Metab. 2013; 98: E1334-44. http://dx.doi. org/10.1210/jc.2013-1053

[43] SCHMIDT Y, SIMUNOVIC F, STRASSBURG S, PFEIFER D, STARK GB, et al. miR-126 regulates platelet-derived growth factor receptor- $\alpha$ expression and migration of primary human osteoblasts. Biol Chem. $2015 ; 396: 61-70$. http://dx.doi. org/10.1515/hsz-2014-0168

[44] HEINRICH MC, GRIFFITH D, MCKINLEY A, PATTERSON J, PRESNELL A, et al. Crenolanib inhibits the drug-resistant PDGFRA D842V mutation associated with imatinib-resistant gastrointestinal stromal tumors. Clin Cancer Res. 2012; 18: 4375-84. http://dx.doi. org/10.1158/1078-0432.CCR-12-0625

[45] CASSIER PA, FUMAGALLI E, RUTKOWSKI P, SCHOFFSKI P, VAN GLABBEKE M, et al. Outcome of patients with platelet-derived growth factor receptor alpha-mutated gastrointestinal stromal tumors in the tyrosine kinase inhibitor era. Clin Cancer Res. 2012; 18: 4458-64. http://dx.doi. org/10.1158/1078-0432.CCR-11-3025

[46] LOVATT M, BIJLMAKERS MJ. Stabilisation of $\beta$-catenin downstream of T cell receptor signalling. PLoS One. 2010; 5: e12794. http://dx.doi.org/10.1371/journal.pone.0012794

[47] KORSMEYER SJ, GROSS A, HARADA H, ZHA J, WANG $\mathrm{K}$, et al. Death and survival signals determine active/inactive conformations of pro-apoptotic BAX, BAD, and BID molecules. Cold Spring Harb Symp Quant Biol. 1999; 64: 343-50. http://dx.doi.org/10.1101/sqb.1999.64.343

[48] WURSTLE ML, LAUSSMANN MA, REHM M. The central role of initiator caspase- 9 in apoptosis signal transduction and the regulation of its activation and activity on the apoptosome. Exp Cell Res. 2012; 318: 1213-20. http://dx.doi.org/10.1016/j. yexcr.2012.02.013

[49] MORGAN DO. The Cell Cycle: Principles of Control. Oxford University Press/New Science Press, Corby (United Kingdom). 2007. 